\title{
Fast hemostasis: a win-win strategy for ultrasound and microwave ablation
}

This article was published in the following Dove Press journal: OncoTargets and Therapy

\author{
Jiabao Guol,* \\ Guo Tian ${ }^{1,2, *}$ \\ Qiyu Zhao' \\ Tian'an Jiang ${ }^{1,2}$ \\ 'Department of Ultrasound Medicine, \\ The First Affiliated Hospital, Zhejiang \\ University School of Medicine, \\ Hangzhou, China; ${ }^{2}$ Key Laboratory \\ of Precision Diagnosis and Treatment \\ for Hepatobiliary and Pancreatic \\ Tumor of Zhejiang Province, \\ Hangzhou, China \\ *These authors contributed equally \\ to this work
}

\begin{abstract}
Introduction: Hemorrhage is a serious complication following percutaneous biopsy requiring detecting and immediate treatment of active bleeding. This study aimed to explore the potential benefits of ultrasound (US)-guided microwave ablation (MWA) to treat acute hemorrhage in risky locations.
\end{abstract}

Materials and methods: We present seven patients (four males and three females) aged 19-69 years with solid-organ arterial hemorrhage treated by US-guided MWA and followed up with contrast-enhanced US (CEUS).

Results: All seven cases successfully underwent MWA for hemostasis, and their vital signs subsequently stabilized. During the follow-up from 13 to 36 days, the ablation area decreased slowly in five patients and was still stable in two cases. There were no complications observed in this study after MWA treatment. We also reviewed a total of 12 publications in the past 10 years. Conclusion: This study suggested that US-guided MWA may be an effective and safe strategy for acute hemorrhage in the emergency setting. To confirm this method and benefit more patients, more prospective studies with larger samples and longer follow-ups are recommended.

Keywords: hemorrhage, hemostasis, microwave, ablation, sonography, contrast-enhanced US, biopsy

\section{Background}

Percutaneous biopsy is the main diagnostic method of tissue tumors. Although more and larger size biopsy specimens have enabled more reliable pathology results, it has increased the risk of hemorrhage from arterial sources, ${ }^{1,2}$ which requires detecting and immediate action against massive active bleeding. Traditional hemostasis methods, such as surgical practice with clamping, suturing, ${ }^{3,4}$ or removing the bleeding parts of the organs, have been performed, which occasionally fail due to central artery rupture, suture-induced tissue infarction, and pseudoaneurysm formation ${ }^{5}$ and thus add to the total expenditure. Another common technology is transcatheter angiographic embolization (TAE), ${ }^{6}$ although the radiation may be hazardous and cause severe complications $^{7}$ and might not be easily accessible and available. Compared to these approaches, thermal ablation - particularly microwave ablation (MWA) - would ablate bleeding vessels under color Doppler flow imaging (CDFI) or contrast-enhanced ultrasound (CEUS), reaching the target tissue and causing faster and larger-scale irreversible tissue coagulation and necrosis in the treated region. MWA has been mainly used in the treatment of active hemorrhage of livers, and its feasibility has been confirmed in both animal studies and clinical practice. ${ }^{8-10}$ However, few publications have reported MWA for bleeding in greater risk locations such as the thyroid, spleen, and thoracic wall. This study aimed to summarize the potential benefits of US-guided MWA to treat acute hemorrhage and to preliminarily evaluate its therapeutic effect. cc) ${ }_{\mathrm{BY}} \mathrm{NC}$ and incorporate the Creative Commons Attribution - Non Commercial (unported, v3.0) License (http://creativecommons.org/licenses/by-nc/3.0/). By accessing the work you hereby accept the Terms. Non-commercial uses of the work are permitted without any further permission from Dove Medical Press Limited, provided the work is properly attributed. For permission for commercial use of this work, please see paragraphs 4.2 and 5 of our Terms (https://www.dovepress.com/terms.php). 


\section{Case series}

We prospectively included seven patients (four males and three females) aged 19-69 years, whose main complication was solid-organ hemorrhage caused by biopsy, interventional operation, or trauma from December 2013 to September 2016. This clinical trial was registered in ClinicalTrials.gov ID: NCT03026452, and the procedure was approved by the ethics committee of The First Affiliated Hospital of Zhejiang University. All patients signed written informed consents and were informed of the risk and advantages of MWA for hemostasis. The baseline of these cases in the study is summarized in Table 1. Eligible patients met the following criteria: (1) ultrasound (US) clearly found arterial bleeding, bleeding spots with velocity $>100 \mathrm{~cm} / \mathrm{s}$; (2) US detected hematoma, along with continuous fall of hemoglobin $(\mathrm{Hb})$ and blood pressure levels; (3) the bleeding position was deep, and the 5-min surface pressure for hemostasis was invalid if bleeding velocity was $<100 \mathrm{~cm} / \mathrm{s}$. Among these seven cases, hemorrhages appeared in two cases caused by spleen biopsy (Figure 1A and B), liver biopsy (Figure 2A-C), or percutaneous transhepatic cholangial drainage (PTCD). In two cases, hemorrhages had been induced by thyroid biopsy (Figure 3A-C), and one resulted from trauma in the thoracic wall (Figure $4 \mathrm{~A}$ and $\mathrm{B}$ ). The mean of $\mathrm{Hb}$, heart rate (HR), and velocity in these cases was $111.7 \pm 35.0 \mathrm{~g} / \mathrm{L}, 98.9 \pm 16.3$ beats $/ \mathrm{min}$, and $88 \pm 18.5 \mathrm{~cm} / \mathrm{s}$, respectively. Furthermore, CEUS successfully detected the hemorrhages, and free fluid was available in all cases, which contributed to the location of the bleeding with US and hematoma.

All patients received conservative therapies such as realtime monitoring under US, local pressing with US probe, or US-guided injection of hemostatic drugs into hemorrhage regions. However, improvement was not observed. One patient, whose $\mathrm{Hb}$ declined continuously following spleen biopsy, was in shock, and her vital signs were unstable. Two other patients with thyroid biopsies to obtain pathologic diagnosis experienced uncontrollable bleeding even after pressing the puncture point for $30 \mathrm{~min}$.

Under sonographic guidance, we selected CDFI patterns to observe active bleeding and to estimate its velocity by pulse wave $(\mathrm{PW})$. When active bleeding velocity was faster than $100 \mathrm{~cm} / \mathrm{s}$, MWA was considered. CEUS was performed to locate the target area before MWA. Then a 15-gauge microwave electrode was inserted into the bleeding sites, which were ablated by the output power of $50-100 \mathrm{~W}$ with 2,450 MHz for 6-8 min using ECO (ECO Medical, Nanjing, China). During the procedure, the electrode was retracted by $1.5-2 \mathrm{~cm}$ to ablate small leaking vessels during ablation. The

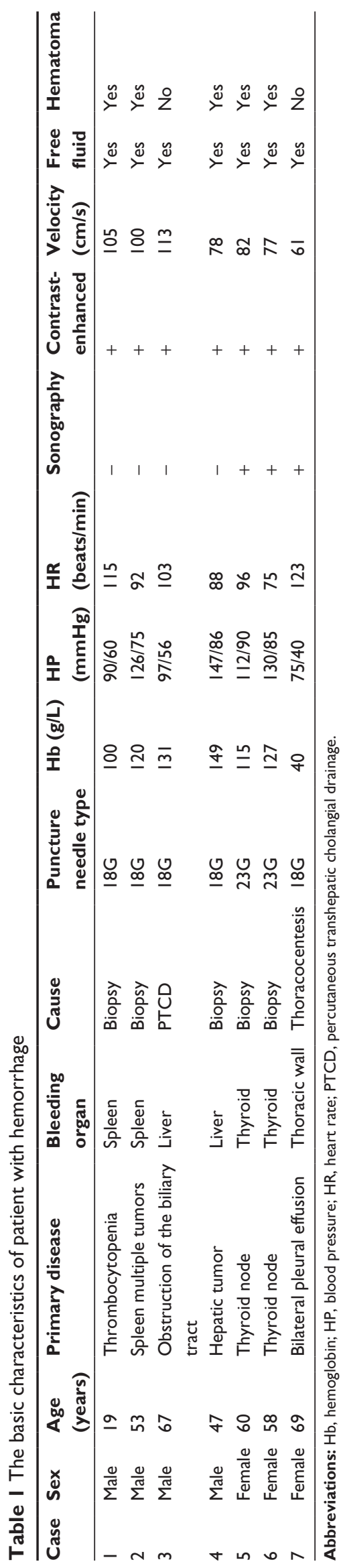



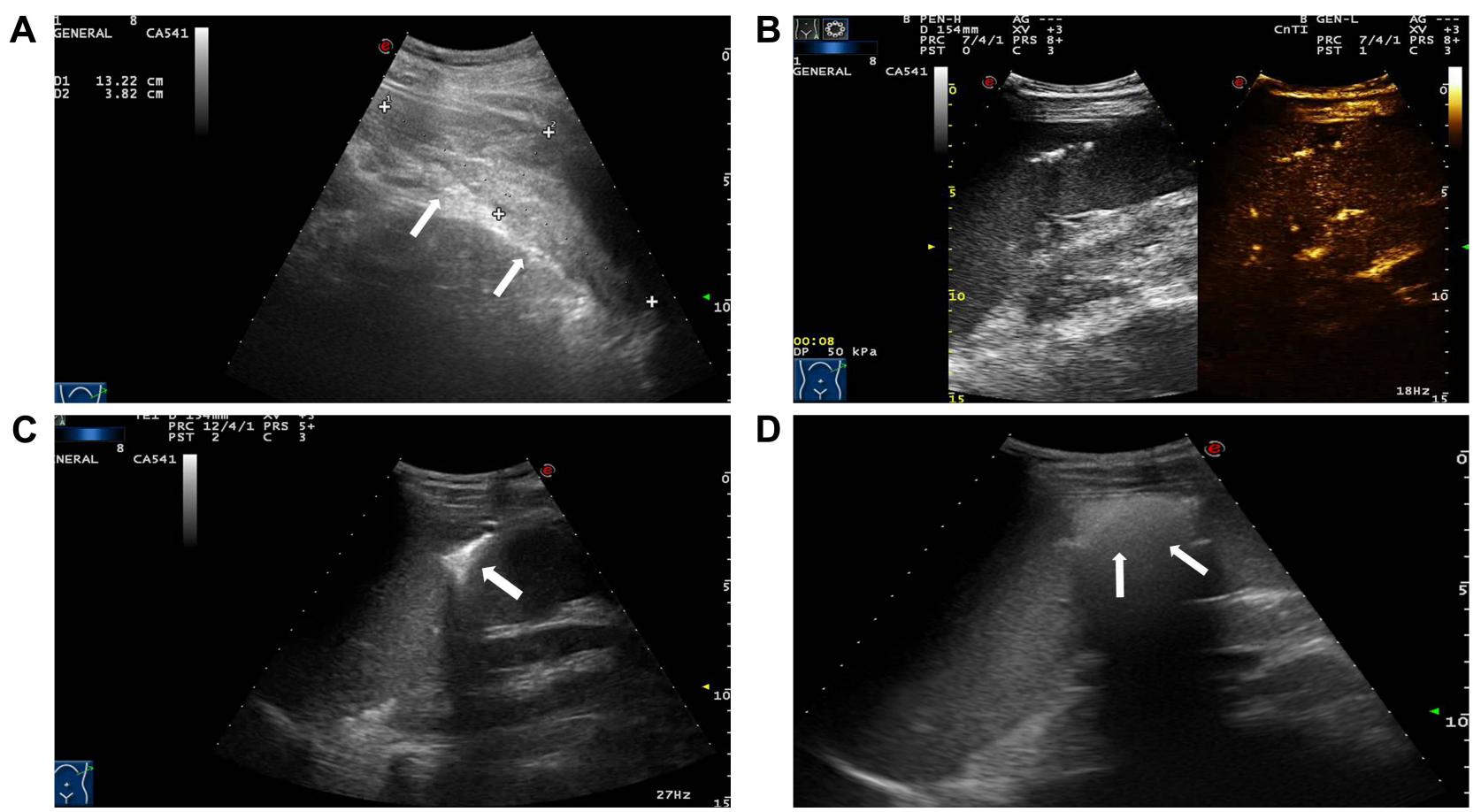

Figure I (A) Crescent-shaped hematoma around the spleen as detected by sonography (arrowheads). (B) Enhanced hemorrhage of puncture tract on contrast-enhanced ultrasound (CEUS). (C) Ultrasound (US)-guided microwave electrode was set into the hemorrhage region (arrowhead). (D) After ablation, enhancement was not detected in the ablation zone (arrowheads).
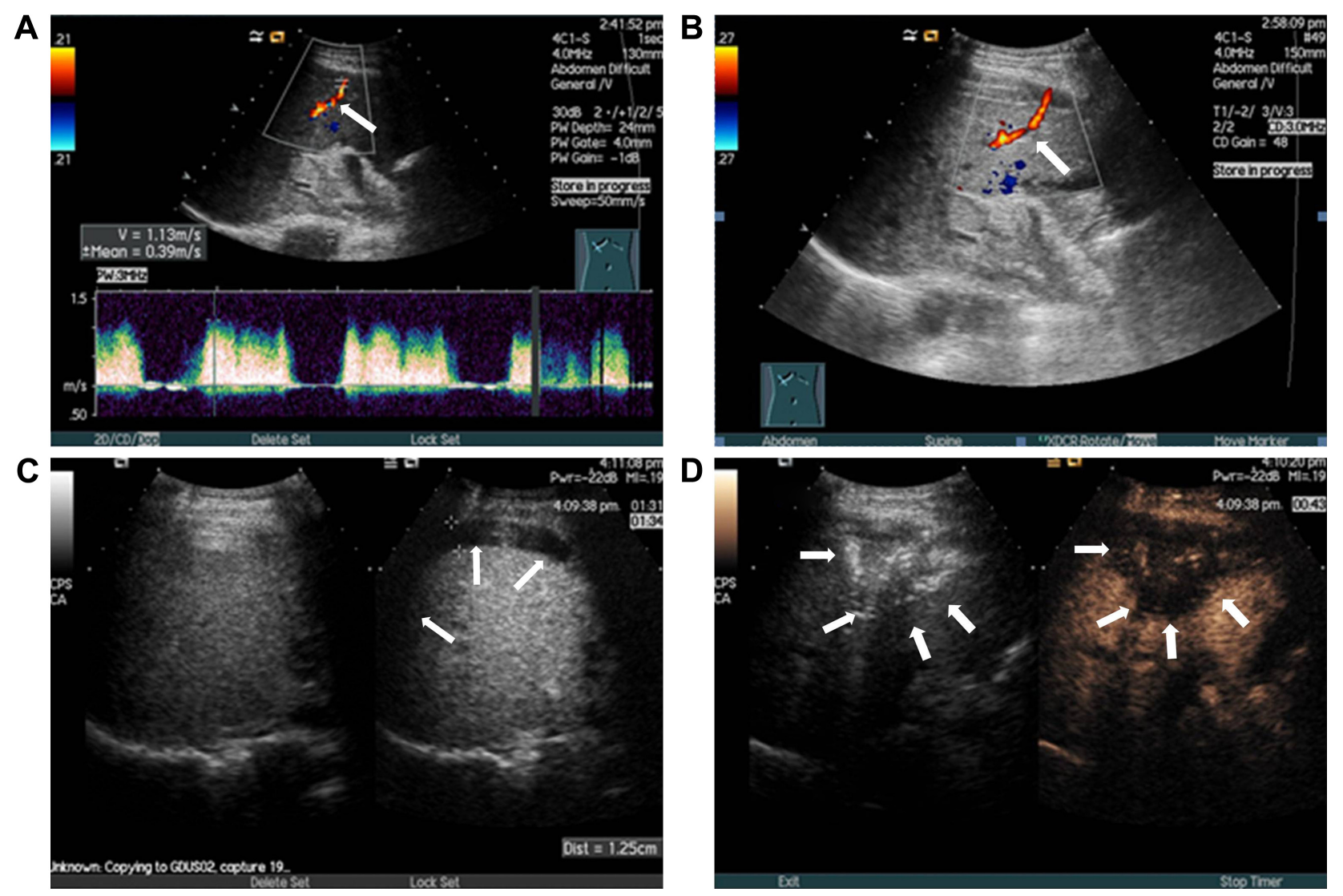

Figure 2 (A and B) Active bleeding originated from the puncture tract with a velocity of $1.13 \mathrm{~m} / \mathrm{s}$ (arrowheads). (C) A $1.3 \mathrm{~cm}$ crescent-shaped free fluid was detected by sonography around the liver (arrowheads). (D) After microwave ablation, contrast-enhanced sonography did not show any microbubble extravasation inside the liver (arrowheads). 
A

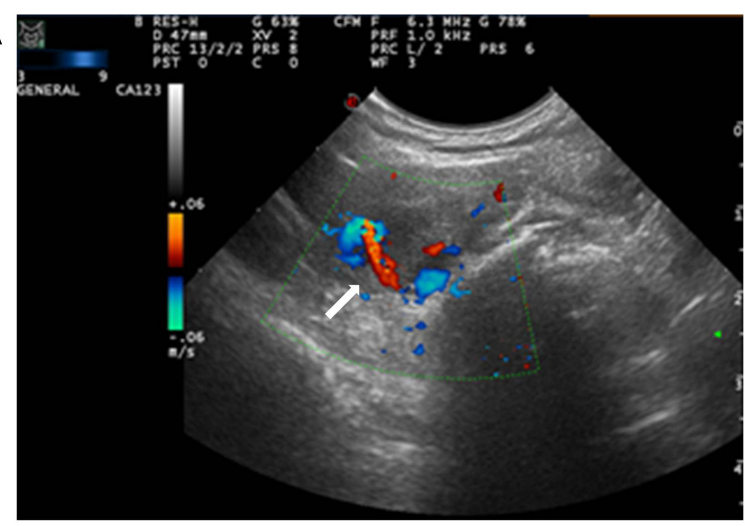

C

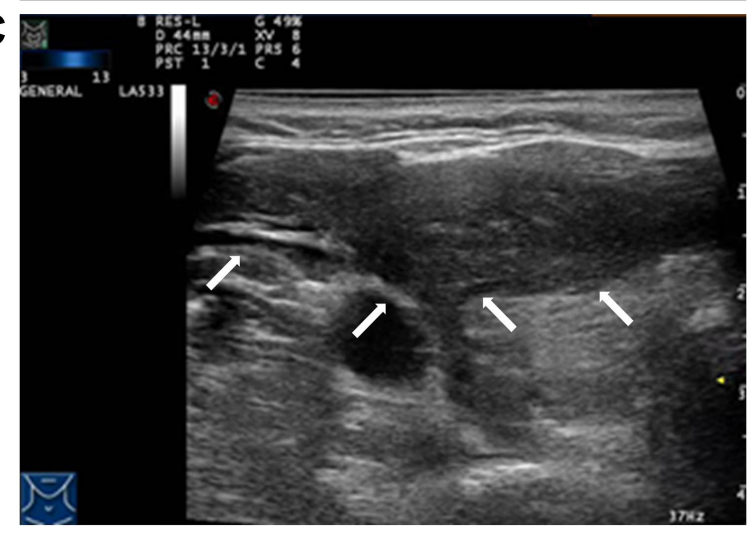

B

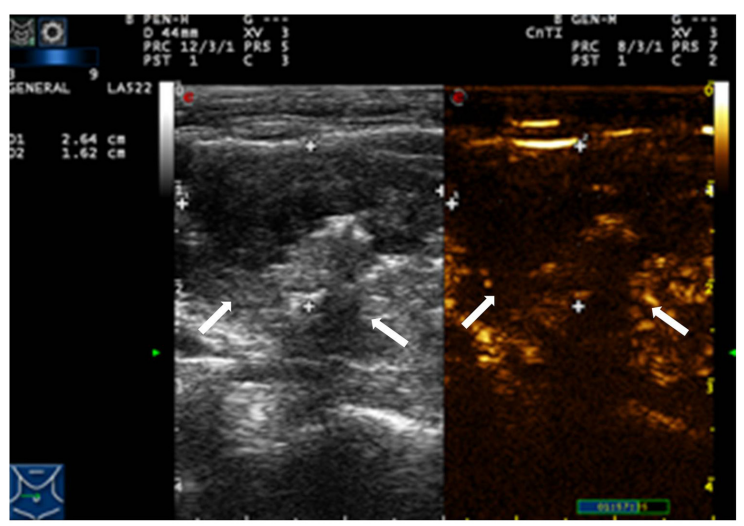

D

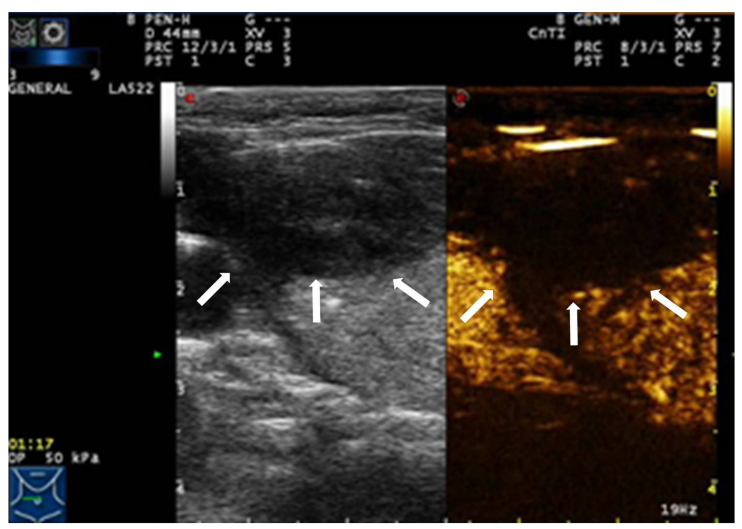

Figure 3 (A) Active bleeding lesion was detected along with small bleeding vessels leaking to the thyroid surface (arrowhead). (B) Contrast-enhanced sonography showed an irregular hematoma measuring $2.6 \times 1.6 \mathrm{~cm}$ around the right thyroid (arrowheads). (C and D) Irregular hematoma was detected around the right thyroid, and ablation region showed no enhancement on contrast-enhanced sonography (arrowheads).
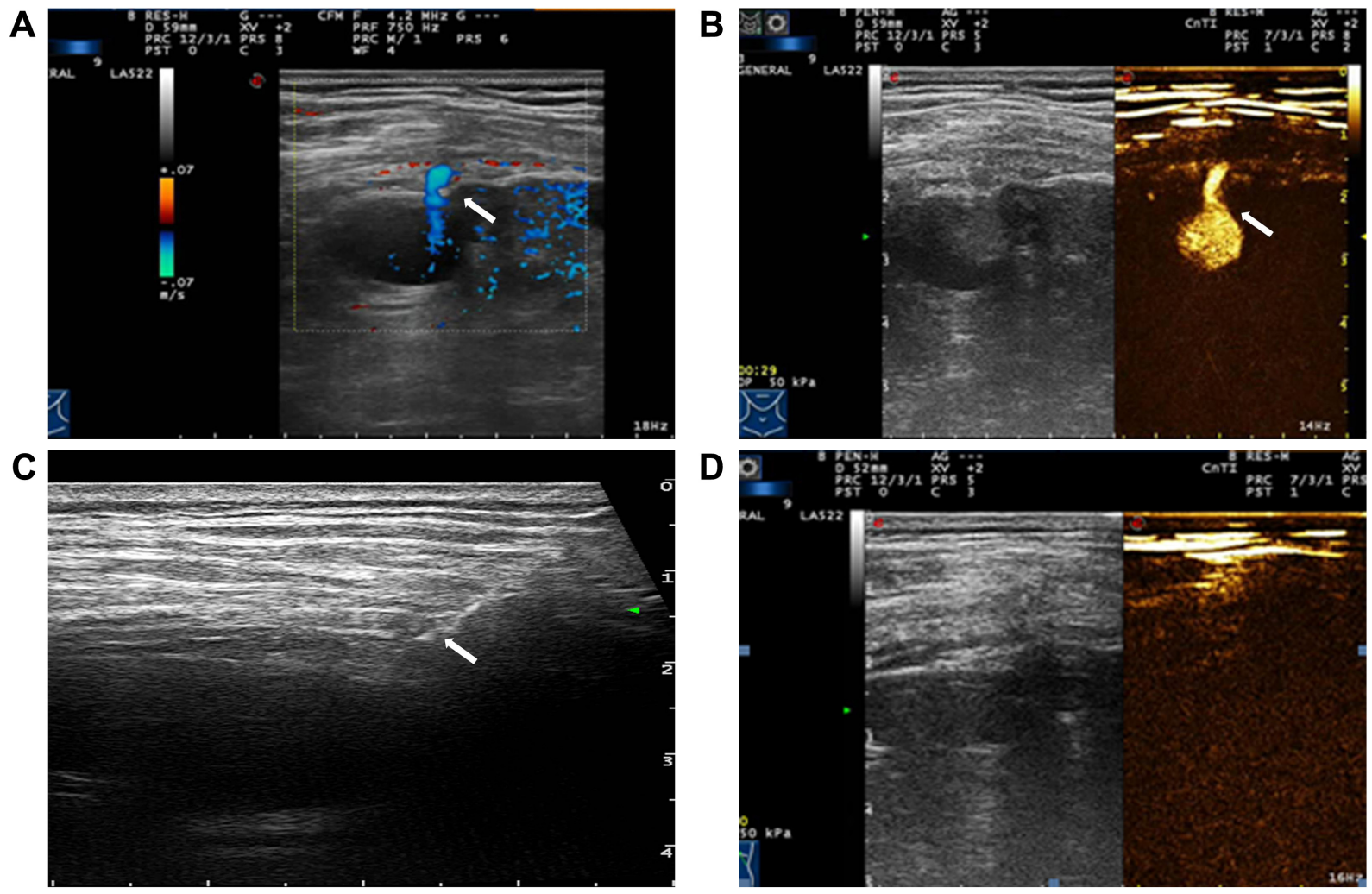

Figure 4 (A and B) Active bleeding originated from a branch of thoracic wall artery (arrowheads). (C) Ultrasound (US)-guided microwave ablation (MWA) (arrowhead). (D) Visible microbubbles extravasation was not observed in this section of hemostasis. 
results depended on the microwave frequency and whether treated tissues were coagulated. The hemostatic effect gradually increased with increasing power until carbonized tissues prevented heat conduction.

To estimate the effects of MWA for hemostasis, CEUS was performed immediately using SonoVue (Bracco SpA, Milan, Italy) after interventional therapy. Successful hemostatic criteria were as follows: first, the hyperechoic area would overlay the entire lesions, and enhancement was not observed in the ablation zones under CEUS. Extravasation of the contrast agent was also not detected around the target organs or tissue spaces. Finally, all vital signs including decreased HR that was within the normal range and elevated blood pressure subsequently stabilized. Hemostasis failure was considered when CEUS showed microbubble extravasation in the trauma regions after ablation, or when the electrocardiogram (ECG) monitor showed unstable blood pressure and HR. When hemostasis was unsuccessful after the first treatment, a second ablation was performed immediately. When interventional hemostasis therapy had not been available after three attempts, open surgery was required immediately.

\section{Results}

Table 2 presents the detailed procedures and outcomes of US-guided ablation for each case. During the procedures, increased temperature made the bleeding coagulated, and the bleeding speed reduced. Then tissues around the electrodes were coagulated slowly, and there was no abnormally fast blood flow around the bleeding spot, indicating that hemostasis was successfully available. After MWA, enhancement was not detected in the ablation zone (Figures $1 \mathrm{C}$ and D, 2D, $3 \mathrm{C}$ and $\mathrm{D}$, and $4 \mathrm{C}$ and $\mathrm{D}$ ).

Patients' blood pressure rose gradually to the normal after MWA and became stable. During the follow-up of 13 to 36 days, the ablation area decreased slowly in five patients and was still stable in two cases. There were no complications observed in this study after MWA treatment.

Table 2 The detailed description in the procedures of microwave ablation (MWA) for hemostasis

\begin{tabular}{llllll}
\hline Case & $\begin{array}{l}\text { Parenchymal/ } \\
\text { vessel injury }\end{array}$ & $\begin{array}{l}\text { Power } \\
\text { (W) }\end{array}$ & $\begin{array}{l}\text { Time } \\
\text { (min) }\end{array}$ & $\begin{array}{l}\text { Follow-up } \\
\text { (days) }\end{array}$ & $\begin{array}{l}\text { Ablation } \\
\text { area }\end{array}$ \\
\hline I & Spleen parenchymal & 100 & 4 & 28 & Decreased \\
2 & Spleen parenchymal & 80 & 6 & 36 & Decreased \\
3 & Liver parenchymal & 100 & 4 & 22 & Stable \\
4 & Liver parenchymal & 100 & 5 & 18 & Decreased \\
5 & Thyroid vessel & 40 & 2 & 26 & Decreased \\
6 & Thyroid vessel & 40 & 2 & 30 & Decreased \\
7 & Thoracic wall vessel & 40 & 1 & 13 & Stable \\
\hline
\end{tabular}

In addition, we reviewed a total of 12 publications from PubMed, Scopus, and Web of Science before April 2017 documenting thermal ablation for hemostasis following biopsy or surgical resection (Table 3) ${ }^{11-22}$ In the literature review, nine studies reported the efficacy of MWA/radiofrequency ablation (RFA)/percutaneous ethanol injection (PEI) on 22 patients (aged 29-83 years, five males and 17 females) with solid-organ bleeding from uterine, liver, and spleen. They suggested $90.9 \%$ efficiency rate without major complications.

\section{Discussion}

Solid-organ hemorrhage deriving from trauma is a serious condition requiring immediate diagnosis and treatment. In our hospital, US-guided tissue biopsy, which involves various solid organs such as thyroid, breast, prostate, liver and spleen, was performed in $\sim 3,000$ cases every year. The number of thermal ablation treatments for solid-organ tumors increased to 720 last year. With such a huge amount of interventional operations, the occurrence of various complications like hemorrhage is inevitable, amounting to $\sim 0.7 \%(0.4 \%$ slight bleeding using surface pressure for hemostasis and $0.3 \%$ severe bleeding by MWA against solid-organ hemorrhage).

Baseline sonography is not sensitive to guide the insertion of ablation needles in the treatment of abdominal solid organ injury. Sonography is a reliable screening tool for detecting active bleeding in combination with CDFI pattern, particularly with the presence of continuous free fluid in the abdominal cavity or hematoma in the tissue space. In particular, CEUS could show real-time and contrast-related images via microbubbles produced, and CEUS was clearer in detecting hemorrhagic spots and assessing the degree of damage. ${ }^{23-25}$ Several studies showed that CEUS is a potential tool that is nearly as sensitive as contrast-enhanced-computed tomography (ceCT) for the detection of traumatic abdominal organ injuries. ${ }^{26,27}$ Moreover, the proposed method has no radiation hazard and is a safer contrast agent compared to ceCT.

Previous studies showed that RFA decreased blood loss in hepatectomy both in animal and clinical experiences. ${ }^{28}$ The temperature in RFA increased slowly, and heat was easily taken away by vessels. Thus, it could not reach the target temperature, and the limited coagulation zone size was an important issue in RFA. ${ }^{11}$ Compared with RFA, MWA depended less on tissue impedance and has a larger zone of active heating. ${ }^{19,29}$ MWA enabled the microwave antenna in the targeting tissue to locally obtain an average temperature of $65^{\circ} \mathrm{C}-100^{\circ} \mathrm{C}$ in seconds, resulting in its coagulation necrosis, which made it possible to quickly 


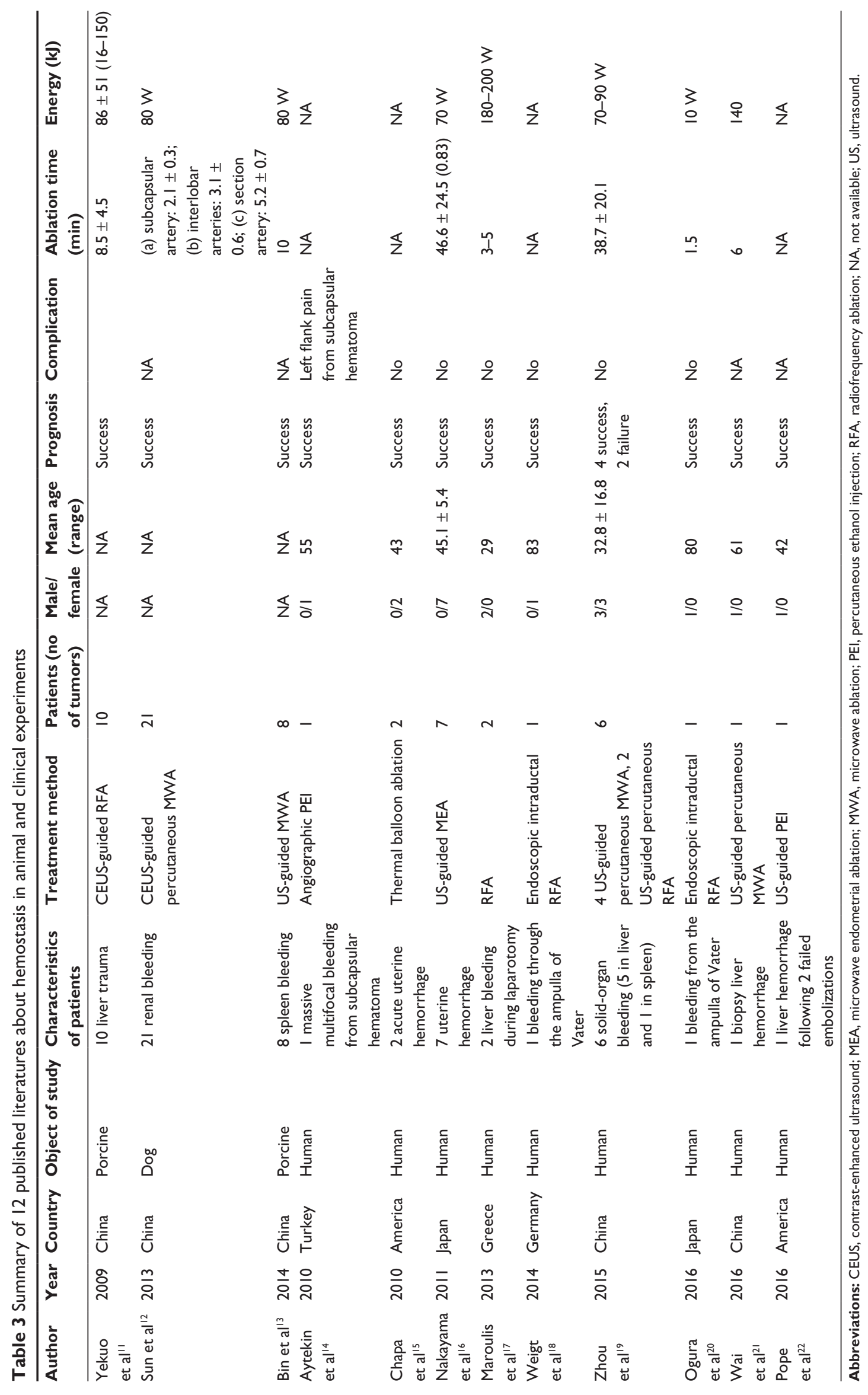


achieve hemostasis and lower the cost without any radiation hazard and major complications from TAE. ${ }^{7}$ Additionally, contrast agent in angiography may increase the metabolic burden of liver and kidney while contrast agent in CEUS not due to its pulmonary pathway for discharge. Some studies also demonstrated that modified MWA has a larger ablative range and higher top temperatures than the previous one because of their longer wavelength, deeper penetration depth, and lower energy attenuation. ${ }^{30,31}$ Thus, MWA was useful for controlling life-threatening hemorrhages even when active bleeding occurred in a larger diameter vessel.

The main limitation of this study was its small sample size and the short-term follow-up, which may have impact on the delayed bleeding if possible. The existing heat-sink in MWA may limit tissue heating and tissue ablation.

\section{Conclusion}

US-guided percutaneous MWA may be an effective and safe strategy for hemostasis in patients with hemorrhage in the emergency setting. To verify this method and benefit more patients, more prospective studies with larger samples and longer follow-ups are needed.

\section{Acknowledgments}

This study was supported by the opening foundation of the State Key Laboratory for Diagnosis and Treatment of Infectious Diseases, Collaborative Innovation Center for Diagnosis and Treatment of Infectious Diseases, The First Affiliated Hospital of Medical College, Zhejiang University, grant No 2015KF06. This study was also supported by the Foundation of Zhejiang Health Committee, grant No 2017 KY346.

\section{Disclosure}

The authors report no conflicts of interest in this work.

\section{References}

1. Rabeea A, Siddiqui AB, Rizwan Khan MT, Sunder S, Waqar K. Bleeding complications post ultrasound guided renal biopsy - a single centre experience from Pakistan. Ann Med Surg. 2017;21:85-88.

2. Sandrasegaran K, Thayalan N, Thavanesan R, et al. Risk factors for bleeding after liver biopsy. Abdom Radiol. 2016;41(4):643-649.

3. Barton JK, Popok DP, Black JF. Thermal analysis of blood undergoing laser photocoagulation. IEEE J Sel Top Quantum Electron. 2001;7(6): 936-943.

4. Nguyen VP, Kim J, Ha KL, Oh J, Kang HW. Feasibility study on photoacoustic guidance for high-intensity focused ultrasound-induced hemostasis. J Biomed Opt. 2014;19(10):105010.

5. Zhang G, Sun Y, Yu J, et al. Microwave coagulation therapy and drug injection to treat splenic injury. J Surg Res. 2014;186(1):226-233.

6. Zentai C, Grottke O, Spahn DR, Rossaint R. Nonsurgical techniques to control massive bleeding. Anesthesiol Clin. 2013;31(1):41-53.

7. Letoublon C, Morra I, Chen Y, Monnin V, Voirin D, Arvieux C. Hepatic arterial embolization in the management of blunt hepatic trauma: indications and complications. J Trauma. 2011;70(5):1032-1036.
8. Song HP, Yu M, Zhang J, et al. Hemostasis of active bleeding from the liver with percutaneous microwave coagulation therapy under contrast-enhanced ultrasonographic guidance: an experimental study. J Ultrasound Med. 2008;27(6):867-874.

9. Valentino M, Serra C, Zironi G, De Luca C, Pavlica P, Baroxxi L. Blunt abdominal trauma: emergency contrast-enhanced sonography for detection of solid organ injuries. Am J Roentgenol. 2012;186: 1361-1367.

10. Yanar H, Ertekin C, Taviloglu K, Kabay B, Bakkaloglu H, Guloglu R. Nonoperative treatment of multiple intra-abdominal solid organ injury after blunt abdominal trauma. J Trauma. 2008;64(4):943-948.

11. Yekuo L, Shasha W, Feng H. Multipolar radiofrequency ablation in controlling hemorrhage from blunt liver trauma. Am J Emerg Med. 2009;27(2):197-201.

12. Sun Y, Zhang G, Dong L, et al. [Study of percutaneous coagulation therapy of $915 \mathrm{MHz}$ microwave for the renal artery injury guided by contrast ultrasound in vivo dogs]. Chin J Clin. 2013;22(14): 6443-6447. Available from: http://www.wanfangdata.com.cn/details/ detail.do?_type=perio\&id=zhlcyszz201314053\#. Accessed February 28, 2018. Chinese.

13. Bin X, Ningming Z, Weitian C, et al. [Experimental study of ultrasoundguided cold circulation microwave ablation in treating splenic trauma]. Chn J Ultra Med. 2014;30(1):69-71. Available from: http://www. wanfangdata.com.cn/details/detail.do?_type=perio\&id=zgcsyxzz201 401022. Accessed February 28, 2018. Chinese.

14. Aytekin C, Yildirim UM, Ozyer U, Harman H, Boyvat F. Emergency renal ablation for life-threatening hemorrhage from multiple capsular branches during renal artery stenting. Cardiovasc Intervent Radiol. 2010;33:663-666.

15. Chapa HO, Antonetti AG, Sandate J, Silver L. Emergent thermal balloon ablation for acute uterine hemorrhage: a report of 2 cases. J Reprod Med. 2010;55:511-513.

16. Nakayama K, Rahman MT, Rahman M, et al. Microwave endometrial ablation is a highly efficacious way to emergently control life-threatening uterine hemorrhage. Arch Gynecol Obstet. 2011;283(5):1065-1068.

17. Maroulis I, Spyropoulos C, Kalogeropoulou C, Karavias D. Use of radiofrequency ablation for controlling liver hemorrhage in the emergency setting; report of two cases and review of the literature. Turk $J$ Trauma Emerg Surg. 2013;19(2):167-172.

18. Weigt J, Kandulski A, Malfertheiner P. Endoscopic intraductal radiofrequency ablation of remnant intrapapillary mucinous neoplasm with acute hemorrhage after incomplete surgical resection. Endoscopy. 2014;46(S 01):E489-E490.

19. Zhou L, Kuang M, Xu Z, Xie X, Lu M. Contrast-enhanced sonographically guided thermal ablation for treatment of solid-organ hemorrhage preliminary clinical results. J Ultrasound Med. 2015;34: 907-915.

20. Ogura T, Takagi W, Ueno S, Takeuchi T, Fukunishi S, Higuchi K. Endoscopic hemostasis for tumor bleeding using intraductal radiofrequency ablation. Endoscopy. 2016;48(S 01):E328-E329.

21. Wai OK, Ng LF, Yu PS, Chan JC. Post biopsy liver hemorrhage successfully controlled by ultrasound-guided percutaneous microwave ablation. J Clin Imaging Sci. 2016;6:34.

22. Pope MC, Ballard DH, Sticker AL, Ahuja C, D'Agostino HB. Ethanol ablation in postbiopsy liver hemorrhage following two failed embolizations. Clin Imaging. 2016;40(1):156-160.

23. Tang J, Lv F, Li W, et al. Contrast-enhanced sonographic guidance for local injection of a hemostatic agent for management of blunt hepatic hemorrhage: a canine study. Am J Roentgenol. 2008;191(3): W107-W111.

24. Valentino M, Serra C, Pavlica P, Barozzi L. Contrast-enhanced ultrasound for blunt abdominal trauma. Semin Ultrasound CT MR. 2007; 28(2):130-140.

25. Zhang G, Dong L, Tai Y, et al. Contrast-enhanced sonographically guided percutaneous 915-mhz microwave ablation therapy compared to local hemostatic drug injection in a renal artery injury model. J Ultrasound Med. 2014;33(4):611-621. 
26. Thorelius L. Emergency real-time contrast-enhanced ultrasonography for detection of solid organ injuries. Eur Radiol. 2007;17 Suppl 6(6):F107-F111.

27. Valentino M, Serra C, Pavlica P, et al. Blunt abdominal trauma: diagnostic performance of contrast-enhanced US in children - initial experience. Radiology. 2008;246(3):903-909.

28. Peng Y, Morris DL. Radiofrequency ablation-assisted liver resection: review of the literature and our experience. HPB (Oxford). 2006;8(4): $248-254$.

29. Kontos M, Felekouras E, Drakos E, et al. Radiofrequency tissue ablation in an experimental model of grade IV renal trauma: a preliminary report. Surg Endosc. 2005;19(2):249-253.
30. Sun Y, Cheng Z, Dong L, Zhang G, Wang Y, Liang P. Comparison of temperature curve and ablation zone between $915-$ and $2450-\mathrm{MHz}$ cooled-shaft microwave antenna: results in ex vivo porcine livers. Eur J Radiol. 2012;81(3):553-557.

31. Wang Y, Sun Y, Feng L, Gao Y, Ni X, Liang P. Internally cooled antenna for microwave ablation: results in ex vivo and in vivo porcine livers. Eur J Radiol. 2008;67(2):357-361.

\section{Publish your work in this journal}

OncoTargets and Therapy is an international, peer-reviewed, open access journal focusing on the pathological basis of all cancers, potential targets for therapy and treatment protocols employed to improve the management of cancer patients. The journal also focuses on the impact of management programs and new therapeutic agents and protocols on

\section{Dovepress}

patient perspectives such as quality of life, adherence and satisfaction. The manuscript management system is completely online and includes a very quick and fair peer-review system, which is all easy to use. Visit http://www.dovepress.com/testimonials.php to read real quotes from published authors. 